Research report

\title{
Long term follow-up study of non-invasive brain stimulation (NBS) (rTMS and tDCS) in Parkinson's disease (PD). Strong age-dependency in the effect of NBS
}

\author{
Judit Málly $^{\mathrm{a}, *}$, Trevor W. Stone ${ }^{\mathrm{b}}$, Gabriella Sinkóa ${ }^{\mathrm{a}}$, Noémi Geisz ${ }^{\mathrm{a}}$, Elek Dinya ${ }^{\mathrm{c}}$ \\ ${ }^{a}$ Institute of Neurorehabilitation, Major-köz 3., Sopron, Hungary \\ ${ }^{\mathbf{b}}$ Institute of Neuroscience, University of Glasgow, Glasgow, G12 8QQ, United Kingdom \\ ${ }^{\mathrm{c}}$ Semmelweis University, Digital Health Department, Budapest, Hungary
}

\begin{abstract}
A B S T R A C T
Background: Transcranial magnetic stimulation (rTMS) may influence the progression of PD compared with levodopa. The long term mind modification effect of repeated rTMS and tDCS is not known, nor are the predictors for the effect of NBS.

Objective/hypothesis: We hypothesized that the regularly repeated rTMS would decrease the development of PD. Later, the treatment protocol was completed with transcranial direct current stimulation (tDCS), supposing that there is an add-on effect. NBS may differently influence motor and mental aspects of the disease.

Methods: Thirty patients with PD were followed for 3.5 years in an open study. They were stimulated with $1 \mathrm{~Hz}$ rTMS every half year for 1.5 years. After that the tDCS was add to the stimulation over both sides of the cerebellum for the next 2 years. UPDRS, Trail Making Test and dual tests were used. The linear regression lines of score systems and percentage of yearly increment were counted, analyzed by ANOVA.

Results: The yearly progression rate for UPDRS total was $2 \%$ for 3.5 years, $0.6 \% \leq 65$ years, $3.6 \%>65$ years. The increment was around zero during the rTMS + tDCS stimulations in patients $\leq 65$ years. The slope of the equation showed the same tendency. The individual sensitivity to the NBS was high. tTMS and tDCS $>65$ yrs improved pathological executive function $(\mathrm{p}<0.0001)$.

Conclusion: The motor ability in PD was maintained at the same level in patients $\leq 65$ years with NBS for the 3.5 years in contrast to patients $>65$ years. The cognitive function of patients $>65$ yrs was favorable influenced by rTMS and tDCS. Age is the main predictor of the effect of NBS. rTMS and tDCS can slow the progression of PD without any side effects but in an age-dependent way.
\end{abstract}

\section{Introduction}

Parkinson's disease (PD) produces progressive declines throughout the patient's life. The change in the quality of life is determined by genes (Hariri et al., 2003; Cheeran et al., 2008; Lipsky and Marini, 2007; Paul et al., 2016; Davis et al., 2016; Escott-Price et al., 2015) and environmental factors (Simon et al., 2015; Moccia et al., 2016). However, the environmental factors cannot be strictly separated from genetic abnormalities because they interact (Simon et al., 2017). Progression of the disease is not linear (Reinoso et al., 2014) and cannot be effectively influenced by drugs. The ADAGO study (Olanow et al., 2009) assumed that rasagiline may reduce the progression rate of PD but 4 years later this hypothesis has not been confirmed (Rascol et al., 2016). Furthermore, stimulation of the subthalamic nucleus did not slow down the progression of PD (Lilleeng et al., 2014). The age-dependency of the progression of the disease was stressed in a follow-up study for 9 years (Hely et al., 1995). The importance of gender, tremor dominant subtype and cognitive status deeply influence the progression of PD. The appearance of dementia and postural instability predicts the worsening of PD (Hely et al., 1995; Evans et al., 2011). The progression rate was different in the follow-up studies (Reinoso et al., 2014; Hely et al., 1995; Di Battista et al., 2016; Liu et al., 2015a, 2015b; Erro et al., 2016; Pedersen et al., 2017; Mendes et al., 2016). They agreed that the appearance of non-motor symptoms significantly depressed the quality of life of patients with PD, even if their motor ability was the same (Erro et al., 2016). Several days of repetitive transcranial magnetic stimulation (rTMS) decreases the Parkinsonian symptoms for months (Málly et al., 2017; Khedr et al., 2003, 2006) but its long term effect on the

\footnotetext{
* Corresponding author.

E-mail address: dr.habil.mallyjudit@gmail.com (J. Málly).
} 
Table 1

Demographic data of patients involved into the study.

\begin{tabular}{|c|c|c|c|c|c|c|c|c|}
\hline & $\begin{array}{l}\text { Number of } \\
\text { patients }(\mathrm{N})\end{array}$ & Age in years & Gender F/M & $\begin{array}{l}\text { Education in } \\
\text { years }\end{array}$ & $\begin{array}{l}\text { Duration of the disease } \\
\text { in years }\end{array}$ & $\begin{array}{l}\text { Tremor/ } \\
\text { Akinezis }\end{array}$ & $\begin{array}{l}\text { Dose of levodopa at baseline } \\
\text { in } \mathrm{mg}\end{array}$ & Hoehn-Yahr stage \\
\hline $\begin{array}{r}\text { Under } 65 \\
\text { years }\end{array}$ & 16 & $58.6 \pm 7.5$ & $1.5 \pm 0.5$ & $15.3 \pm 3.0$ & $6.2 \pm 3.3$ & $1.4 \pm 0.5$ & $334.3 \pm 184.1$ & $1.31 \pm 0.58$ \\
\hline $\begin{array}{r}\text { Above } 65 \\
\text { years }\end{array}$ & 14 & $72.1 \pm 3.8$ & $1.0 \pm 0.2$ & $16.5 \pm 1.3$ & $4.6 \pm 3.4$ & $1.4 \pm 0.5$ & $321.4 \pm 191.8$ & $1.53 \pm 0.49$ \\
\hline
\end{tabular}

development of PD is not known. The rTMS as an add-on therapy to levodopa substitution slowed the progression of Parkinson's disease, compared with the group receiving the drug alone (Málly et al., 2004). However, the long term mind modification effect of regularly repeated rTMS and tDCS is not known. Furthermore, the predictors of the effects of treatment with non-invasive brain stimulation are not known. By the end, our long-term follow-up study compared rTMS stimulation with the rTMS plus tDCS. Motor disability and executive function were studied in the early phase of Parkinson's disease for 3.5 years.

\section{Materials and methods}

\subsection{Patients}

The study was approved by the Regional Ethics Committee of the Petz Aladár University Teaching Hospital in Győr, Hungary.

Thirty patients with PD in the Hoehn-Yahr I-II stage (Hoehn and Yahr, 1967) were involved in the study. The demographic data are included in Table 1. At the baseline, patients did not have postural instability, dementia, or dyskinesia. Their motor state was steady during the day. No patient had the tremor dominant form of the disease. Patients took slow release levodopa with a dopa decarboxylase inhibitor and also entacapone in a separate tablet (at the dose 300-600 mg/day) (Fig. 5). A dopamine receptor agonist was not used. All patients with PD reacted well to levodopa. Patients were tested while taking the drugs. They were examined before the study, at the end of the stimulation and after one month of non-invasive brain stimulation. The stimulation with rTMS and later rTMS plus tDCS was repeated every half year for three and half years (Fig. 1).

\subsection{The applied methods}

The patients were tested with the Unified Parkinson Disease Rating Scale (UPDRS) (Fahn and Elton, 1987), a Trail Making Test (Reitan, 1992) and a dual test. The dual test had three parts. The time to walk a distance of $25 \mathrm{~m}$ was measured. The measurement was repeated counting back from 100 by 3 and by 7 . We measured the distance a patient could walk in $6 \mathrm{~min}$ and the time to walk $10 \mathrm{~m}$. A Mini Mental

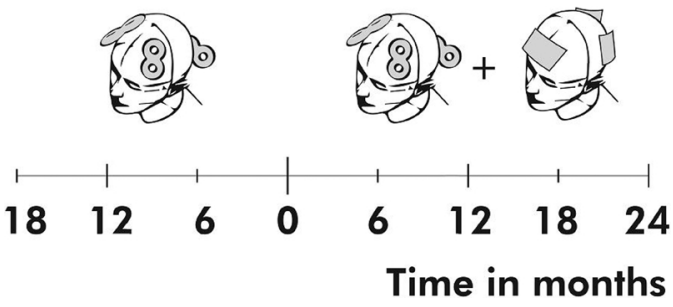

Fig. 1. Protocol of the treatment. Patients $(\mathrm{N}=30)$ were followed for 3.5 years. From -18 months to the 0 point; they got repetitive rranscranial magnetic stimulation (rTMS). The parameters of rTMS were as follows: $1 \mathrm{~Hz}, 25 \%$ of $2.3 \mathrm{~T}$ over the dorsolateral prefrontal cortex (DLPFC) $2 \times 50$ stimulus and $1 \mathrm{~Hz} \mathrm{40 \%}$ of $2.3 \mathrm{~T} 100$ stimulus over the brainstem (Magstim 220). At the zero point, transcranial direct current stimulation was added to rTMS. Anodal stimulation was applied over both hemispheres of the cerebellum with $1 \mathrm{~mA}$ for $20 \mathrm{~min}$. The cathode was placed over the middle part of the frontal area.
Rating Scale excluded the patients with dementia from the study. Patients were tested before the study and then one week, one month and six months after the rTMS treatment. The examinations were performed while patients were taking levodopa with dopamine decarboxylase and cathecol ortho-methyl transferase inhibitors.

\subsection{Protocol for stimulation with repetitive transcranial magnetic stimulation}

One-Hertz stimulation was applied over both dorsolateral-prefrontal cortices (DLPFC) and over the brain stem. Each DLPFC was marked with an EEG cap. The brain stem was marked $2 \mathrm{~cm}$ from the edge of the occipital bone. The intensity was $25 \%$ of the maximum output of the device (2.3 T) (Magstim 220). The intensity was chosen according to a dose-response curve where the optimal intensity for treatment in PD was determined (Málly and Stone, 1999a, 1999b). Fifty stimuli with $25 \%$ of $2.3 \mathrm{~T}$ were given over each DLPFC. One hundred stimuli with $40 \%$ of maximum output were applied over the brain stem. Twelve sessions were done over 7 days.

\subsection{Protocol for stimulation with transcranial direct current stimulation}

The stimulator produced by Magstim (HDC stim ${ }^{T M}$ ) was used. Both anodes were placed over the hemispheres of the cerebellum. The cathode was placed over the middle part of the frontal area. One mA current stimulation was used for 20 min once a day for five days during each treatment period.

\subsection{Statistical analysis}

Results are expressed as the mean \pm standard deviation of mean (S.D.) and sample size (N) for each treatment group. The normality of data was checked by applying the Shapiro-Wilk's test. When nonnormal data could not be rejected, homogeneity of variances was assessed through the Levene's test. Means were compared by a $t$-test or by separately repeated measurements analysis of variance (ANOVAs) with Tukey's correction for multiple comparisons applied where appropriate. The linear regression analysis was made to show the progression of the disease with the scatter plot diagram. The slope of the regression line indicates the progression of the diseases.

The annual increment in percentage was counted. All of the test scores of patients were given as a percentage of total score and are presented for each group of patients. These averages were subtracted from the last value of the followed period. At the end, the average of these differences was defined as the annual increment.

The analysis was two-sided, with a level of significance of $\alpha=0.05$. All statistical analyses were done using the SAS 9.4 (SAS Institute Inc., Cary, NC, USA.) software package.

\section{Results}

The effect of rTMS and rTMS + tDCS on the change of the UPDRS total is demonstrated in Fig. 2. However, there was no significant difference at the baseline between the patients $\leq 65$ years and $>65$ years but the older group showed higher increases compared to the younger group of patients. Patients with $\mathrm{PD} \leq 65$ years had minimal 


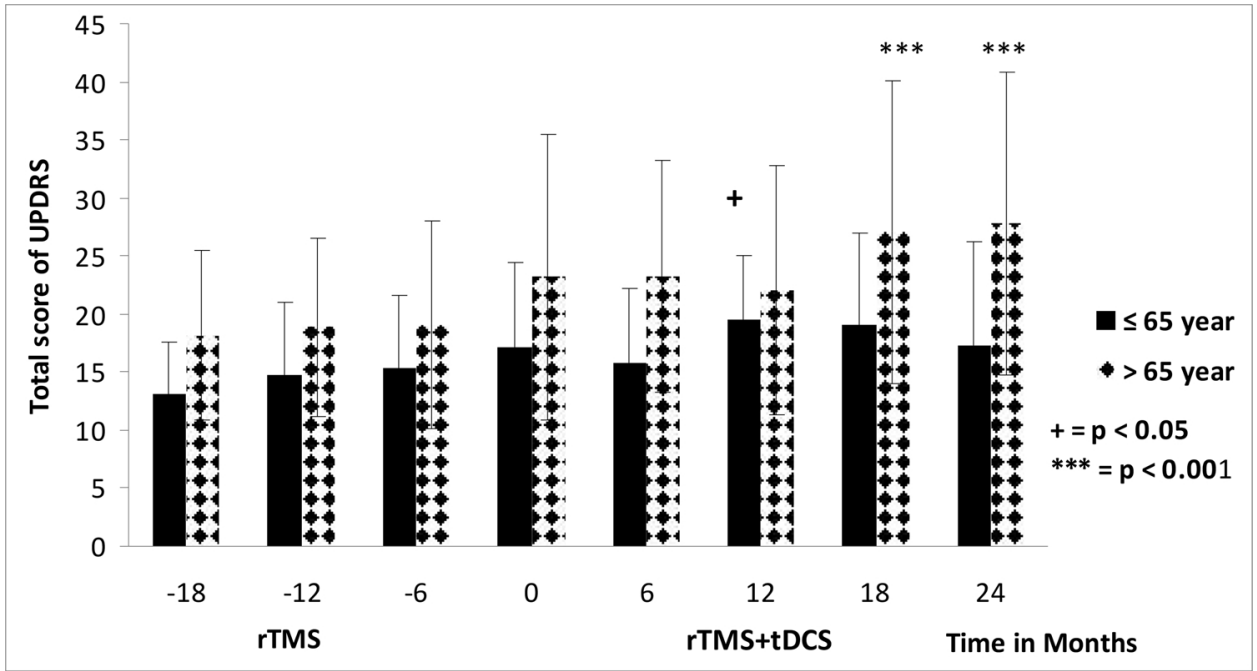

Fig. 2. The progression of Parkinson's disease assessed by UPDRS total $(\mathrm{N}=30)$. Data are given in mean $\pm \mathrm{SD}$. The filled black columns represent patients $\leq 65$ years $(\mathrm{N}=16)$, the dotted columns show patients $>65$ years $(\mathrm{N}=14)$. In every half year (from -18 months to 0 ) they got rTMS with $1 \mathrm{~Hz}$ low intensity for 7 days. At the 0 point, tDCS was added to rTMS. The progression of patients $>65$ years revealed a non-linear progression. The progression became significant, compared to the baseline in the 3rd year $(*=\mathrm{p}<0.001)$. The patients $\leq 65$ years showed a different pattern. They became significantly worse 2.5 years latter $(+=p<0.05)$ compared to the baseline, but their state was equilibrated during the 3.5 follow-up years. There was a significant difference between the two groups from the zero point.
Table 2

The side effects of levodopa at the end of the study. Dyskinesia was higher in the younger group.

\begin{tabular}{lll}
\hline & $\leq 65$ & $>65$ \\
& $\mathrm{~N}=16$ & $\mathrm{~N}=14$ \\
\hline Dyskinesia & 8 & 3 \\
Wearing off & 5 & 4 \\
on-off & 4 & 3 \\
hallucination & 0 & 1 \\
\hline
\end{tabular}

deterioration, which became significant after 2.5 years compared to their values at baseline but later they did not show any significant deterioration. Patients with PD $>65$ years revealed a graduated worsening over years, which became significant after 36 months $(\mathrm{p}<0.001)$. The deterioration was also maintained over 42 months $(\mathrm{p}<0.001)$. The development between the two age groups of patients differed significantly at the point of "0" when the tDCS was added to the rTMS. The significant difference was maintained between the two age groups for the next two years. The UPDRS motor scores of the two groups did not significantly differ. Otherwise values at baseline and at the end of 42 months were in the same range. However, a high standard deviation was observed on each occasion when they were tested indicating that there is a great individual sensitivity to the stimulations. The side effects of levodopa therapy were included in the Table 2.

The development of PD with NBS was analyzed by linear regression lines, where the correlation coefficient and the slope of the equation were given during different stimulation periods. The correlation coefficient of the UPDRS total and the motor score of UPDRS did not show any correlation with time. The correlation coefficient was not significantly different from the time. That is why we took into account the slope of equation, which accurately reflected the progression of the disease. For the whole follow-up period (42 months) $(\mathrm{N}=30)$ the slope of the equation was 0.17992 . The slope of the equation differed in the two age groups counted for the whole follow-up period (Fig. 3. $\leq 65$ years: $0.12510,>65$ years: 0.23190 ). The patients $>65$ had a greater deterioration than the younger patients for 3.5 years (Fig. 3). The two treatment periods were separated. There was no great difference during the administration of rTMS ( -18 to 0 months) between the patients in their equation. Patients $\leq 65$ yrs: $y=16.934+0.21039 *$ Time correlation: $\mathrm{r}=0.22907 \mathrm{p}=0.3933$; patients $>65$ years : $\mathrm{y}=22.116+0.25261$ *Time, correlation: $\mathrm{r}=0.18538 \mathrm{p}=0.5257$. When tDCS was added, the slope of the regression line for patients $\leq 65$ years was 0.06814 (Fig. 4). tDCS significantly slowed the progression of $\mathrm{PD} \leq 65$ years. We do not know if this was an add-on effect of rTMS or the effect tDCS alone. rTMS plus tDCS produced a slope of equation: 0.31045 for patients $>65$ years (Fig. 4). None of the stimulations slowed down the progression of PD in patients $>65$ years. We summarized the progression rates in percentage of different treatment periods (Table 4). The rTMS plus tDCS for two years showed the zero progression rate in the patients $\leq 65$ years, which overlapped the analysis of regression lines. The patients $>65$ years had a much lower progression in UPDRS motor scores under the dual treatments than with the administration of rTMS alone. The different methods showed different progression rates (Table 4).

The linear regression line of their motor scores was nearly zero in both groups of patients However, the standard deviation was extremely high. It reflects a great variation among individuals in their sensitivity to NBS. As the disease progresses, higher doses of levodopa are required. In this study the average dose of levodopa was between $300-450 \mathrm{mg} /$ day, which was nearly stable during the research (Fig. 5). The side effects of levodopa therapy developed at the end of the followed period (Table 3). Dyskinesia was twice as frequent in the younger group of patients as in the older ones. However, it confirmed a good reaction to levodopa. Postural instability $(12-21 \%)$, and a freezing effect (12-14\%) rarely appeared but was in equal proportion in both groups at the end of the study (Table 4). Dementia was not observed. Fatigue and depression appeared in $31 \%$ of the younger group and $21 \%$ of the older group.

The executive function was tested with a Trail Making Test (B-A) (TMT) and dual tests. The executive function assessed by TMT showed no progression (according to regression lines) in age-matched healthy controls $(\mathrm{N}=26)$. Patients with $\mathrm{PD} \leq 65$ years had a slight deterioration over years $\mathrm{y}=16.113+0.12510 *$ time.

The group $>65$ years significantly differed from age-matched healthy controls in their mental achievement at the baseline assessed by TMT B-A (control: $46 \pm 11$ s, PD: $61 \pm 10 \mathrm{~s} \mathrm{p}<0.05$ ). They showed slow, but significant improvement over the 3.5 years (Fig. 6). The dual tests showed the same tendency as TMT. The slope of equation was $y=65.576-0.3302 *$ Time in patients $>65$ years in the dual test counting back by 3 , and the test counting back by 7 $\mathrm{y}=94.820-0.4333^{* *}$ Time.

\section{Discussion}

Lately, many long-lasting observations of patients with PD have been published (Hely et al., 1995; Reinoso et al., 2014; Ding et al., 2016; Kojovic et al., 2015; Di Battista et al., 2016; Mendes et al., 2016; Erro et al., 2016; Pedersen et al., 2017). Our present study demonstrated a favorable influence of regularly repeated non-invasive brain 


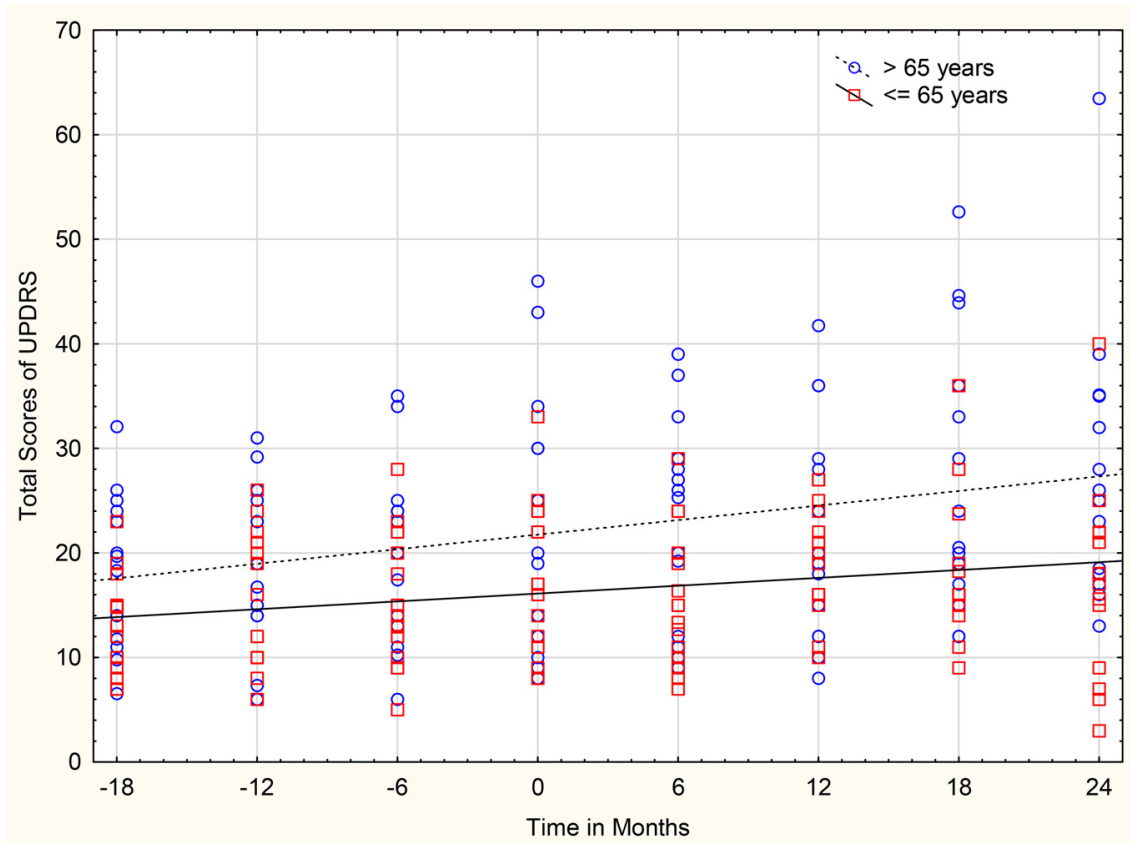

Fig. 3. The effect of rTMS and tDCS on Parkinsonian Symptoms assessed by UPDRS total. Patients $\leq 65$ years $(\mathrm{N}=16)$ (represented by a linear line) and patients $>65$ years (showed by a dotted line) were followed for 3.5 years. rTMS with $1 \mathrm{~Hz}$ from -18 months to the 0 point was given. At this time the tDCS was added to the treatment every half year. Description of linear regression line $\leq 65$ years: $\mathrm{y}=16.113+0.12510 *$ Time, regression line $>65$ years: $\mathrm{y}=21.743+0.23190 *$ Time. stimulation on the progression of the disease. This is the first observation which suggests that beyond the symptomatic effects, NBS affects the progression of PD in an age-dependent way. Both the motor and mental functions of patients with PD were tested in this study, although those functions reacted differently to rTMS and tDCS. The total score of UPDRS, motor score of UPDRS and ADL showed different rates of progression of PD during the distinct stimulations (Table 4) reflecting similar observations by Klawans (1986). According to his results, the symptoms of PD progressed differently over 12 years. The same outcome was produced with electrophysiological measurements evaluated by paired associative stimulation, a silent-period, short-interval intracortical inhibition for one year in 12 patients. There was a great variation in the progression of values and correlation of electrophysiological parameters and motor changes. Therefore the impact of individual progression was stressed (Kojovic et al., 2015). The authors of both papers concluded that individual analysis is better than a group analysis.

The UPDRS total includes the Activities Daily Living (ADL) subscore, which may be one of the best markers for indicating the impact of the progression rate in patients with PD opposite to their motor scores (Harrison et al., 2009). After NBS, the UPDRS motor scores of the patients changed more than their ADL score. While their ADL of patients $\leq 65$ years was significantly changed, there was no convincing decrease in the subjects $>65$ years. Altogether the patients $>65$ years had a higher progression rate (assessed by their UPDRS total) than the younger group. In spite of faster deterioration in these cases, under the dual stimulations, their progression rate did not reach the published percentage. The yearly increment was $2.1 \%$ in their UPDRS total scores and $1.3 \%$ in UPDRS motor scores in the present study. In previous publications, the progression rate in percentage revealed a great

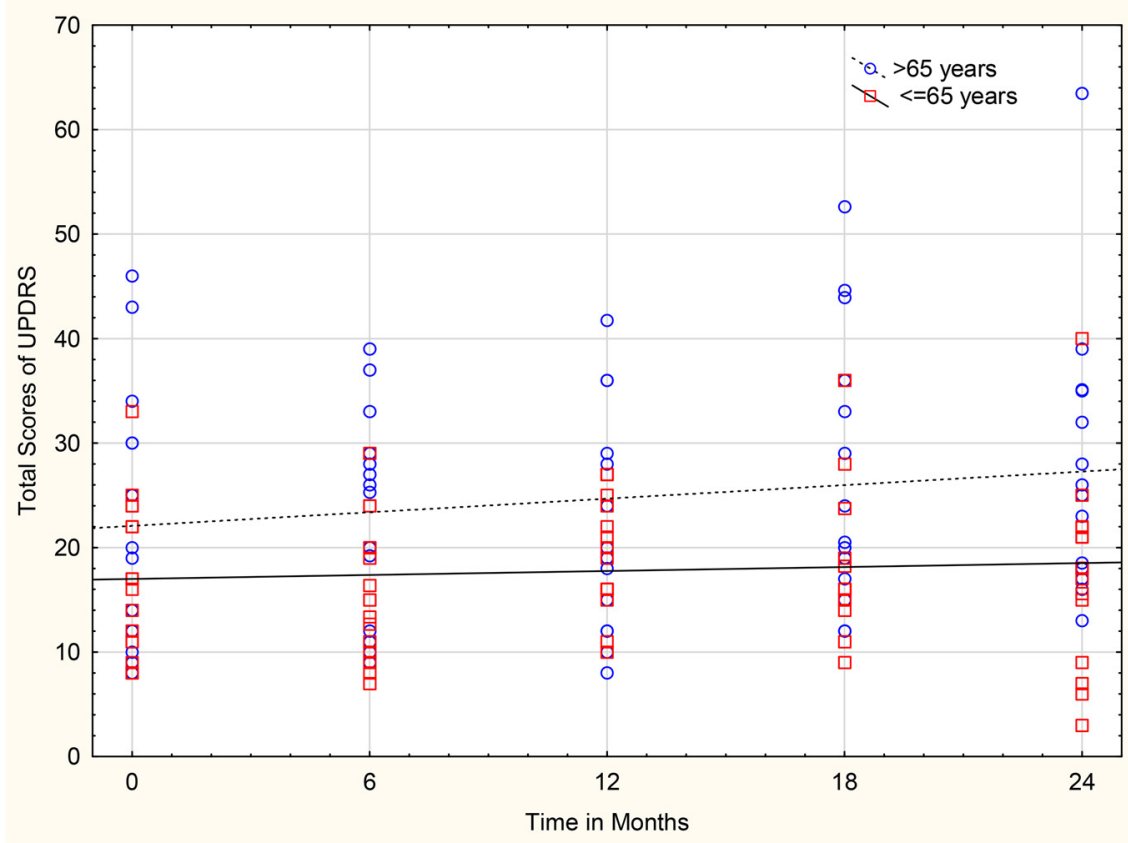

Fig. 4. The effect of rTMS and tDCS on Parkinsonian Symptoms assessed by UPDRS totals. Patients $\leq 65$ years (shown by a continuous line) $(\mathrm{N}=16)$ and $>65$ years (represented by a dotted line) $(\mathrm{N}=14)$ were followed for 2 years. rTMS with $1 \mathrm{~Hz}$ and the tDCS were given every half year. Description of linear regression line $\leq 65$ years: $\mathrm{y}=17.0032+0.0632 *$ Time; $>65$ years $\mathrm{y}=22.0802$ $+0.2159 *$ Time. The ability of patients under 65 years to move was stable during the followed period, while that of patients above 65 years worsened. 


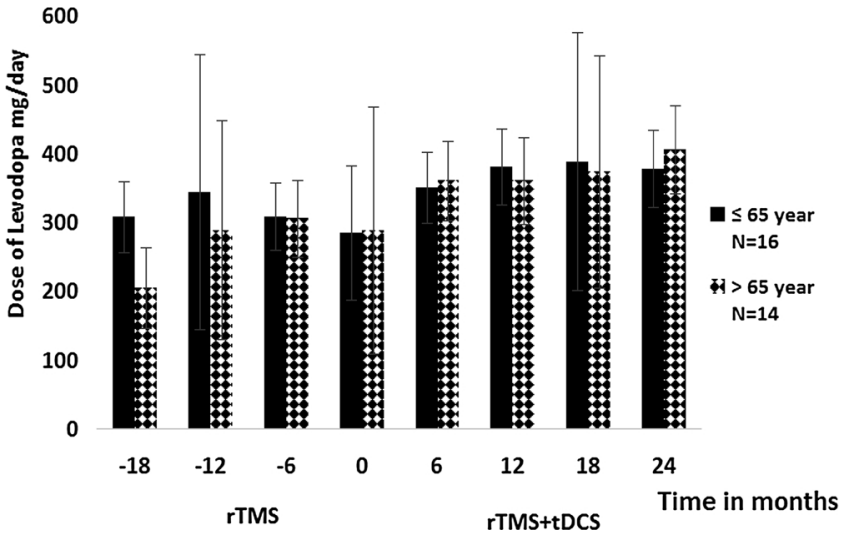

Fig. 5. Change in the dose of levodopa during the followed 3.5 years. Data are given in mean \pm SD. The black columns represent the patients $\leq 65$ years and the dotted columns show the subjects $>65$ years. Patients were treated with repetitive transcranial magnetic stimulation (rTMS) with $1 \mathrm{~Hz}$ for 7 days every half year (from -18 to 0 ). During the next 2 years the rTMS and transcranial direct current stimulation (tDCS) were given together every half year. There was no significant change in the dose of levodopa. The standard deviation was high.

Table 3

The progression of the severity of symptoms at the end of the study. Dementia was not appeared at the end of the study. Postural instability appeared only in few cases by the end of 10 years.

\begin{tabular}{llc}
\hline & $\leq 65$ & $>65$ \\
& $\mathrm{~N}=16$ & $\mathrm{~N}=14$ \\
\hline postural instability & 2 & 3 \\
freezing effect & 2 & 2 \\
fatigue & 5 & 3 \\
depression & 5 & 4 \\
dementia & 0 & 0 \\
\hline
\end{tabular}

Table 4

Annual increments in percentage.The values separately show the UPDRS total scores, Activity of Daily Living (ADL), and UPDRS motor scores in percentage counted in yearly increments. The horizontal columns differentiate between the treatment periods. The patients $(\mathrm{N}=30)$ were separated according to their age. The lowest progression was detected in patients $\leq 65$ years who had the combination of rTMS + tDCS for two years.

\begin{tabular}{|c|c|c|c|}
\hline & UPDRS Total & $\mathrm{ADL}$ & UPDRS Motor \\
\hline \multicolumn{4}{|l|}{ All of the patients } \\
\hline 3.5 years $N=30$ & 2.0 & 2.8 & 0.6 \\
\hline$\leq 65$ years $N=16$ & 0.6 & -0.5 & -0.3 \\
\hline$>65$ years $\mathrm{N}=14$ & 3.6 & 6.5 & 2.8 \\
\hline \multicolumn{4}{|l|}{ All of the patients } \\
\hline-18 to 0 months rTMS & 1.8 & 1.6 & 1.8 \\
\hline$\leq 65$ years $N=16$ & 1.4 & 1.6 & 1.4 \\
\hline$>65$ years $\mathrm{N}=14$ & 2.3 & 1.7 & 2.3 \\
\hline \multicolumn{4}{|l|}{ All of the patients } \\
\hline $0-24$ months rTMS + tDCS & 0.8 & 0.6 & -0.6 \\
\hline$\leq 65$ years $\mathrm{N}=16$ & -0.3 & -1.4 & -0.3 \\
\hline$>65$ years $\mathrm{N}=14$ & 2.1 & 5.1 & 1.3 \\
\hline
\end{tabular}

variation. The yearly increment ranged between $1.2 \%$ and $3.8 \%$ depending on the applied scores (Mendes et al., 2016). They confirmed in their study that the different progression rates belonged to different Parkinsonian symptoms. In our previous study, where the yearly increment was $2.8 \%$ in the group receiving levodopa alone, the group treated with levodopa plus rTMS there was a $0.94 \%$ progression in nonselected patients (Málly et al., 2004). Other authors found the following results. A study by Alves et al. (2005) reported an average motor score of $3.1 \%$, ADL of $3.5 \%$, and nearly the same results were presented by Louis et al. (1999), who published an annual score of 3.6\%, with subscores of 2-3.1 \% (Alves et al., 2005; Louis et al., 1999). Different results were published by Reinoso et al. (2014) whose patients had UPDRS motor scores from baseline ranging from $0.62 \%$ to $3.67 \%$. Annual decline in the total score of UPDRS was 1.34 (on-phase) and annual decline: 1.38 in the off-phase was reported by Jankovic (Jankovic and Kapadia, 2001). However, the slope for total scores was 2.97 and 1.38 for motors scores, which is much higher than our presented data. This diversity of results may come from the arrangement of the studies because patients with different severity of PD were collected for a long term observation; furthermore the length of time of the follow-up of patients varied between 3 and 8 years (Jankovic and Kapadia, 2001). The progression rate was higher at both the onset of the disease and in the late phase of the disease (Lee et al., 1994; Schrag et al., 2007; Maetzler et al., 2009). In the late stage of PD, postural instability and dementia appear frequently, which are probably resistant to levodopa treatment (Hely et al., 2005, 2008; Ding et al., 2016). At onset of the disease, the progression of motor disability is faster (Ding et al., 2016). The yearly increment was $2.3 \%$ in the off-phase published by Ding et al. (2016). There was a 4 year follow up study of 124 patients in the late phase of their disease. One of the studies published motor and disability scores which ranged from 2.4 to $7.4 \%$ per year (Schrag et al., 2007).

In this study, we evaluated patients in the middle phase of their disease. They were involved in the experiment when they had their symptoms for nearly 6 years and they were examined at least 10 years after the onset of their disease. This period of 3.5 years may cover the middle period where the progression of the disease was steady. We restricted the variability of progression by eliminating patients with dementia or postural instability; we included only the Hoehn-Yahr I-II stages with a similar duration of the disease. In spite of the small number of patients in the two homogenous groups (which differed only in age), we can prove a favorable effect of rTMS and rTMS + tDCS on the progression of PD. The slopes of the equations were nearly zero during the administration of rTMS + tDCS, assessed by UPDRS totals and their motor scores in the group $\leq 65$ years, which was confirmed by counting the percentage of the annual increment. None of the published studies demonstrated this low progression rate as in our study with NBS.

The studies endeavored to determine the predictive signs of the progression of the disease. In the following paragraphs we will discuss the impact of daily activity, gait imbalance, the role of levodopa administration on the progression rate, and examinations in on-off phases. Furthermore, we will consider the age of patients when they were involved in the treatment, and discuss the effect of their cognitive ability on the progression of $\mathrm{PD}$.

One of the studies emphasized that the Activity of Daily Living (ADL) was a good prognostic factor to estimate the progression of the disease (Harrison et al., 2009). We discussed it above in detail with our results.

The other predictive symptom in the progression of Parkinson's disease was the gait imbalance (Ellis et al., 2016; Williams-Gray et al., 2013). The impact of the gait/postural stability was also stressed with factor analysis (Evans et al., 2011). Symptoms collected in one factor tended to progress inexorably with time but they did not correlate with each other in their development through time. It seemed that it was one of the causes of observed heterogeneity of PD. The onset of postural instability is important in the prognosis of PD (Evans et al., 2011). It was confirmed that a gait/balance disorder was a better predictor than the early presence of tremor (Hershey et al., 1991). In our study over 3.5 years, the appearance of signs of the progression of the disease was also revealed. Postural instability appeared in two cases $\leq 65$ years and three cases $>65$ years at the end of the follow-up study, when the duration of the disease had been about 10 years in both groups of patients. We counted the percentage of symptoms. It was $12-21 \%$ for postural instability in the two age groups and $12-14 \%$ for the freezing 


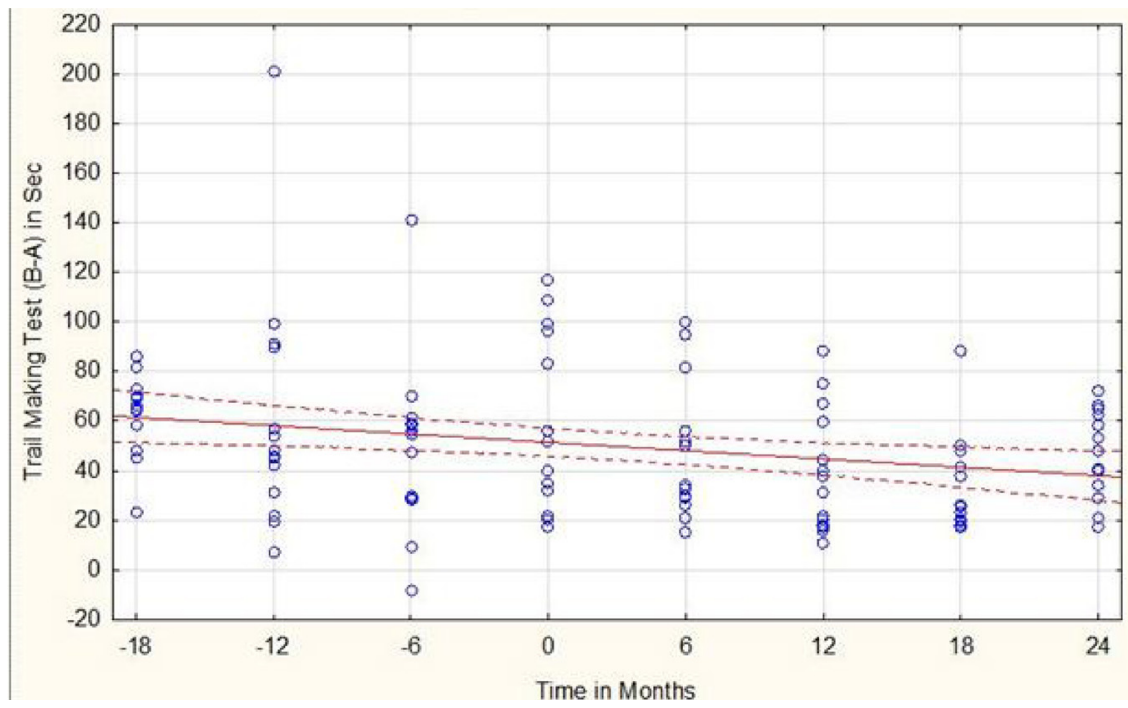

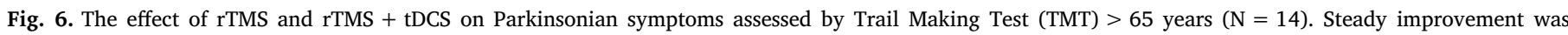
observed mainly after the rTMS and tDCS. The description of linear regression line: $\mathrm{y}=51.447-0.5600{ }^{*}$ Time, correlation: $\mathrm{r}=-0.2539 \mathrm{p}=0.3810$.

effect. We may suppose that the rTMS stimulations over the brain stem and tDCS over both hemispheres of the cerebellum played a role in these favorable effects.

The cerebellum also takes part in the motor and mental circuits (Schniepp et al., 2017; Mentis et al., 2003). Its important role in Parkinson's disease was reviewed by Wu and Hallett (2013). It is emphasized that the gait disturbance, which is the cardinal symptom of PD, may be caused by the hypoactivation of the anterior lobe of the cerebellar hemisphere, hyperactivation of the cerebellar vermis and also the activation changed in many other brain regions assessed by singlephoton emission computed tomography (PET) (Hanakawa et al., 1999). The potential role in the freezing of the function of the pedunculopontine nucleus was highlighted in the brain stem (Schweder et al., 2010; Fraix et al., 2013). We can summarize that the cerebellum plus its connections and the brain stem have a pathological role in the symptoms of PD. We stimulated these regions by rTMS with $1 \mathrm{~Hz}$ and anodal tDCS. However, we can not distinguish between the effects of the two stimulations; we suppose that the reduction of postural instability and freezing effect may come from the dual stimulation over the cerebellum and the brain stem. Stimulations over the cerebellum can modulate the intracortical primary motor cortex activity (Fierro et al., 2007), which may further have an add-on mechanism for the healing effect of NBS over the cerebellum. Our results coincide with other outcomes after stimulation of the cerebellum. The therapeutic effect in alleviating resting tremor was published by (Lefaivre et al., 2016) and relieving gait ataxia was described by (Manto and Ben Taib, 2008; Bonni et al., 2014). Stimulations over the cerebellum were reviewed by other researchers (Grimaldi et al., 2016; Franca et al., 2017).

However, fatigue and depression reached $30 \%$ in both age groups. We did not observe dementia at the end of the study. In spite of the small number of patients, these are very important observations, because the quality of life is extremely worsened when non-motor symptoms appear, mainly dementia and postural instability (Hely et al., 1999). According to a 4 year longitudinal study, the appearance of nonmotor symptoms significantly increased over time (Erro et al., 2016), like difficulty in swallowing, sleepiness, restless legs syndrome, and hallucinations (Maetzler et al., 2009). Dopamine therapy has a little impact on them.

Although treatment with levodopa has been used for 50 years and it has a good symptomatic effect in PD, its effect on the development of Parkinson's disease has not been confirmed (Hely et al., 1999; Fahn et al., 2004). However, in a double-blind study with different doses of levodopa for 42 weeks (ELLDOPA) after the wash-out period which lasts for 2 weeks, the group treated with a high dose of levodopa showed a better state assessed by their UPDRS total scores than the placebo group (Parkinson Study Group, 2004). This raises the possibility that levodopa has an effect on the progression of PD but the long term favorable symptomatic effect cannot be excluded because the effect of levodopa may persist for two weeks during the wash-out period. It takes 32 days to eliminate $90 \%$ of the drug (Hauser and Holford, 2002). It seems that the tenth "anniversary" is very important in the life of patient with PD. The motor symptoms get better or are maintained for nearly ten years but the quality of life steadily deteriorates. Hoehn and Yahr (1967) indicated that within the first 10 years there is no difference between the patients under 50 years and over 50 years. According to Reinoso et al., (2014) during the first 6.5-7 years, the progression rate was lower, assessed by UPDRS motor scores, but later it increased (between 0.62 and 3.67\%). The progression of the disease without levodopa was studied in Africa (Cilia et al., 2014). Their conclusion was that motor fluctuation and dyskinesia are not associated with the duration of treatment with levodopa, even with a longer duration of the disease and a higher levodopa dose (Cilia et al., 2014). No clinicopathological study could confirm the effect of levodopa on the progression of the disease. Ninty-seven patients were studied after their deaths. The study showed that there was no difference in the Lewy body and other pathologies between the dopa responsive and nonresponsive cases. The pathological changes varied according to the age and duration and manifestation of disease independently of the patient's response to dopa.(Kempster et al., 2007). In our study, the levodopa dose was not increased during the NBS treatment period. Furthermore, the daily administration of levodopa did not differ significantly between the two age groups. The same observation was made in our earlier study that patients treated with regularly repeated rTMS needed a lower dose of levodopa compared with patients treated with levodopa alone (Málly et al., 2004). It is a very important observation that during the administration of NBS, the dose of levodopa is nearly steady. It is well known that the side effects of levodopa depend on the dose of drug. During NBS treatment, the dose of levodopa can be reduced, which decreases the side effects. In our study the dose of levodopa was not significantly changed over the 3.5 years. We concluded that the rate of progression could not be influenced by levodopa. In all of the progression studies, the gold standard levodopa therapy was given. This way we can compare those studies with our long term follow up study.

The examination during the time the drug was having an effect or withdrawal from it impacts the judgment of the progression of PD. 
Recently, Ding et al. (2016) indicated that the test of patients in the offphase reflected the real progression of the disease. However, there is no pure drug-free period in patients who are regularly treated with levodopa. The progression continues in both phases of the on-phase and the off-phase (Ding et al., 2016; Mendes et al., 2016). In our study the patients were tested in the drug active phase of the day.

The age-dependency of patients was studied widely in the literature. The onset of disease in older age was associated with a faster progression of PD (Hely et al., 1995; Alves et al., 2005; Reinoso et al., 2014; Spica et al., 2013; Wickremaratchi et al., 2009; Levy, 2007; Diederich et al., 2003; Post et al., 2011). The prognostic factor of the age at onset for future motor impairment was highlighted by Post et al. (2007). They declared that the lower age at baseline of the study was related to a slower progression rate. However, dystonia and dyskinesia appeared more frequently in the younger age group of patients than those at onset at an older age (Wickremaratchi et al., 2009). Our study confirms this observation, because in the younger group of patients, dyskinesia was present twice as frequently as in the older group of patients.

This means that they reacted well to levodopa. In agreement with the literature, the younger group progressed more slowly in our study, too. The progression was slower and it stopped during the rTMS plus tDCS stimulation for two years. We concluded that NBS yields better effects in the group $\leq 65$ years than for the older group of patients. However, the effect of NBS on the progression in motor scores $>65$ years cannot be excluded.

Different effects of rTMS and rTMS plus tDCS on motor disability and executive function were observed in this study. A strong age-dependency was detected in the total scores of UPDRS. Furthermore, the rTMS plus tDCS together may have a more significant effect in the development of the disease, according to the value of the slope and the percentage of yearly increment in the younger group of patients. It was demonstrated that rTMS was less effective in the group $>65$ years than in the younger group of patients over a long time. This observation is consistent with the observation that the symptomatic effect of rTMS lasted for a shorter time in the higher age group at baseline (Málly et al., 2017).

Cognitive deterioration and appearance of dementia are prognostic factors for a faster progression rate in PD (Marras et al., 2002; Post et al., 2007). The older age at onset of motor and non-motor symptoms and dementia are related to each other (Auyeung et al., 2012; Poewe, 2009). Cognitive decline gradually advances over time reported by Di Battista et al. (2016) based on a 5-year follow-up study. Thirty-nine percent of patients with PD $(\mathrm{N}=54)$ had a reduced cognitive reserve after 5 years. In their study, the younger aged patients had better cognitive stability, although the individual differences were emphasized in this paper. How mild cognitive impairment progresses to dementia was examined by Pedersen et al. (2017). They found that after 5 years, nearly $40 \%$ of patients suffered from dementia.

According to these disappointing results, our observations are very interesting for the future treatment of PD. The executive function in patients $>65$ years had pathological results which improved gradually by rTMS and rTMS plus tDCS treatment for 3.5 years. It may be argued that the patients might learn the tasks, but in contrast, the younger group of patients showed a slower deterioration of executive function, assessed by TMT. The patients with age-matched healthy controls showed a permanent achievement in their tests during the examined period. According to these observations, we may strongly suppose that the recovery in the restoration of executive function with NBS from pathological values (assessed by TMT and dual tasks) is very promising with respect to future treatments with NBS. We suggest that this new observation with NBS treatment is not a rapid effect; however it is a result of a long term repeated treatments. The improvement was obvious only in the pathological values of executive functions in patients $>65$ years, but the younger group $\leq 65$ years revealed a slight, steady worsening, assessed by TMT over the followed 3.5 years. However, we cannot determine which kind of stimulation is responsible for this effect; whether it relates only to the tDCS stimulation or if it is an add-on effect of rTMS. This favorable effect in patients $>65$ years was continuously shown during both treatments with rTMS and rTMS plus tDCS. There are publications with tTMS and tDCS stimulations indicating improving cognitive function (Rektorova et al., 2005; Cotelli et al., 2006; Antal et al., 2004a, b; Floel et Cohen, 2007; Jahanshahi and Rothwell, 2000; Ilieva et al., 2018; Kavanaugh et al., 2018). The comparison of single with repetitive sessions of stimulations for days with NBS was summarized lately by Buch (Buch et al., 2017).

Different protocols were published with NBS in the treatment of PD (Málly et Stone, 1998; Málly and Stone, 1999a, 1999b; Khedr et al., 2003, 2006; Lomarev et al., 2006; Lefaucheur et al., 2014; Brys et al., 2016; Dragasevic et al., 2002; Shirota et al., 2013; Li et al., 2015; Pál et al., 2010). We do not think that there is only one optimal protocol for the treatment of PD. We suppose that the frequency and intensity are connected with each other. Probably the low frequency is connected with low intensity and high frequency with high intensity as we have discussed previously (Málly et al., 2017). There are different packages of optimal parameters with frequency, intensity, and duration of stimulation working together may each be effective in the treatment with NBS. In this way it may be supposed that there may be more than one package for the treatment of Parkinsonian symptoms, but only $1 \mathrm{~Hz}$ rTMS with low intensity achieved the reduction of development of PD. This protocol not only improves the Parkinsonian symptoms, but the progression of disease has been slowed by the repeated rTMS and rTMS plus tDCS with reduced parameters. The treatment with extremely low intensity was applied in experimental encephalitis with success (Medina-Fernandez et al., 2018).

There are several crucial questions are: (a) which kind of regeneration mechanisms contribute to slowing the speed of PD progression. We cannot answer it directly. According to animal studies, the regeneration processes are based on the elevation of brain derived nerve factor (BDNF) (Müller et al., 2000; Cheeran et al., 2008; Antal et al., 2010) and the increased production of progenitor cells (Arias Carrión, 2008; Guo et al., 2014; Ueyama et al., 2011; Liu et al., 2015a, 2015b; Luo et al., 2017). Stimulation with $1 \mathrm{~Hz}$ was compared with $30 \mathrm{~Hz}$ of stimulation in the brains of adult mice (Abbasnia et al., 2015). The effect of $1 \mathrm{~Hz}$ stimulation started earlier, and more cells were produced than from the stimulation with $30 \mathrm{~Hz}$. Both stimulation levels increased the differentiation of stem cells. However, the change in the brain plasticity was stressed in the literature after the acute, short stimulations for days but this change lasts for a short time (Hassanzahraee et al., 2018, reviewed by Huang et al., 2017). The dopamine level in the striatum is elevated after $1 \mathrm{~Hz}$ or higher frequency stimulations, which explains the symptomatic effects of rTMS. It may overlap the stimulation period and it does not last for a longer time than the stimulation (Strafella et al., 2001, 2005). The much more interesting aspect of the focal stimulation is its influence over the whole brain assessed by studies of microcirculation (Park et al., 2017) and EEG (Chung et al., 2015). Neither drugs nor electric stimulations have this special effect as the rTMS, which may involve non-synaptic connections. The remote effect of rTMS after focal stimulation may induce a non-synaptic transmission mechanism: transmitters are released into the extra-synaptic space. This effect was first published by Vizi (Vizi, 1984; Vizi et al., 2010, 2000, 1993, 1981; Vizi and Burnstock, 1988). The activation of widespread areas of the brain from the focal stimulation explains the variation of observed effects after the stimulation of the primary motor cortex and DLPFC. However, this site of actions can not explain the long lasting remodeling of the brain.

In the last several decades, in in vitro experiments using microperfusion system field stimulation have been used at various frequencies to study the release of various transmitters from slice preparations of the cerebral cortex (Vizi and Burnstock, 1988; Vizi et al., 1989; Matko et al., 1994), hippocampal (Lorincz et al., 2016) striatal (Milusheva et al., 1996) and spinal cord (Umeda et al., 1997; Sircuta et al., 2016; Borbely et al., 2017; Vegh et al., 2017). This method made 
possible to study the interaction between different axon terminals and presynaptic effects of drugs and provided convincing evidence that the release of transmitters from neuronal networks is frequency dependent and at high frequency $(>10 \mathrm{~Hz})$ the release is able to escape from presynaptic, hetero- and autoreceptor-mediated modulation (Knoll and Vizi, 1971). In our previous paper (Mally, 2013; Málly et al., 2017) we started that the non-invasive stimulation (rTMS and tDCS) have frequency-dependent effects on Parkinsonian patients. Nevertheless, in the literature the available data are rather contraversial (Elahi et al., 2009; Chou et al., 2015; Wangle et al., 2016 and Zhu et al., 2015) as far as the frequency of stimulation is concerned. Therefore we conclude that the effect of transcranial stimulation may depend not only on the frequency, but also on the intensity $[\mathrm{U} / \mathrm{d}(\mathrm{V} / \mathrm{mm})]$ of stimulation, as it is in in vitro pharmacological experiments. Accordingly, the mode of action of non-invasive stimulation is to restore functional connectivity among neurons (networks).

At present, we can raise the possibility that there is elevated BDNF and increased production of progenitor cells after the stimulations by rTMS and tDCS, which may play a crucial role in the slower progression of the disease. They may not be responsible for the symptomatic effects of rTMS and tDCS, but they may restore brain connections or networks for a certain time. Although, it is proved that rTMS increases both the BDNF and progenitor cells which are interconnected, their long effect on regenerating processes may need to be proved in the near future.

\section{Conclusions}

In this study, we confirmed the effect of the low intensity, low frequency, regularly repeated rTMS and further the combination of rTMS and tDCS on the progression of Parkinson's disease. This effect of NBS was age-dependent and differently influenced motor and mental functions. The progression rate of motor disability differed from the ADL and the total score of UPDRS. A nearly zero progression in motor disability was observed during the rTMS plus tDCS stimulations in patients $\leq 65$ years, in contrast to the patients $>65$ years. NBS cannot only influence symptoms of PD but also decrease the progression of PD.

\section{References}

Abbasnia, K., Ghanbari, A., Abedian, M., Ghanbari, A., Sharififar, S., Azari, H., 2015. The effects of repetitive transcranial magnetic stimulation on proliferation and differentiation of neural stem cells. Anat. Cell. Biol. 48, 104-113.

Alves, G., Wentzel-Larsen, T., Aarsland, D., Petter-Larsen, J., 2005. Progression of motor impairment and disability in Parkinson disease. A population-based study. Neurology $65,1436-1441$

Antal, A., Nitsche, M.A., Kincses, T.Z., Kruse, W., Hoffmann, K.P., Paulus, W., 2004a. Facilitation of visuo-motor learning by transcranial direct current stimulation of the motor and extrastriate visual areas in humans. Eur. J. Neurosci. 19, 2888-2892.

Antal, A., Nitsche, M.A., Kruse, W., Kincses, T.Z., Hoffmann, K.P., Paulus, W., 2004b. Direct current stimulation over V5 enhances visuomotor coordination by improving motion perception in humans. J. Cognit. Neurosci. 16, 521-527.

Antal, A., Chaieb, L., Moliadze, V., Monte-Silva, K., Poreisz, C., Thirugnanasambandam, N., Nitsche, M.A., Shoukier, M., Ludwig, H., Paulus, W., 2010. Brain-derived neurotrophic factor (BDNF) gene polymorphisms shape cortical plasticity in humans. Brain Stimul. 3, 230-237.

Arias Carrión, O., 2008. Basic mechanism of rTMS: implications in Parkinson's disease. Int. Arch. Med. 15 (2).

Auyeung, M., Tsoi, T.H., Mok, V., Cheung, C.M., Lee, C.N., Li, R., Yeung, E., 2012. Ten year survival and outcomes in a prospective cohort of new onset Chinese Parkinson's disease patients. J. Neurol. Neurosurg. Psychiatry 83, 607-611.

Bonni, S., Ponzo, V., Caltagirone, C., Koch, G., 2014. Cerebellar theta burst stimulation in stroke patients with ataxia. Funct. Neurol. 29, 41-45.

Borbely, Z., Csomo, B.K., Kittel, A., Gerber, G., Varga, G., Vizi, E.S., 2017. Effect of rat spinal cord injury (hemisection) on the ex vivo uptake and release of $[(3) \mathrm{H}]$ noradrenaline from a slice preparation. Brain Res. Bull. 131, 150-155.

Brys, M., Fox, M.D., Agarwal, S., Biagioni, M., Dacpano, G., Kumar, P., Pirraglia, E., Chen, R., Wu, A., Fernandez, H., Shukla, A.W., Lou, J.S., Gray, Z., Simon, D.K., Di Rocco, A., Pascual-Leone, A., 2016. Multifocal repetitive TMS for motor and mood symptoms of Parkinson disease: a randomized trial. Neurology 87, 1907-1915.

Buch, E.R., Santarnecchi, E., Antal, A., Born, J., Celnik, P.A., Classen, J., Gerloff, C., Hallett, M., Hummel, F.C., Nitsche, M.A., Pascual-Leone, A., Paulus, W.J., Reis, J., Robertson, E.M., Rothwell, J., Sandrini, M., Schambra, H.M., Wassermann, E.M., Ziemann, U., Cohen, L.G., 2017. Effects of tDCS on motor learning and memory formation: a consensus and critical position paper. Clin. Neurophysiol. 128, 589-603.
Cheeran, B., Talelli, P., Mori, F., Koch, G., Suppa, A., Edwards, M., Houlden, H., Bhatia, K., Greenwood, R., Rothwell, J.C., 2008. A common polymorphism in the brain-derived neurotrophic factor gene (BDNF) modulates human cortical plasticity and the response to rTMS. J. Physiol. 586, 5717-5725.

Chou, Y.H., Hickey PÍ, T., Sundman, M., Song, A.W., Chen, N.K., 2015. Effects of repetitive transcranial magnetic stimulation on motor symptoms in Parkinson's disease: a systematic review and meta analysis. JAMA Neurol. 72, 432-440.

Chung, S.W., Rogasch, N.C., Hoy, K.E., Fitzgerald, P.B., 2015. Measuring brain stimulation induced changes in cortical properties using TMS-EEG. Brain Stimul. 8, 1010-1020.

Cilia, R., Akpalu, A., Sarfo, F.S., Cham, M., Amboni, M., Cereda, E., Fabbri, M., Adjei, P., Akassi, J., Bonetti, A., Pezzoli, C., 2014. The modern pre-levodopa era of Parkinson's disease: insights into motor complications from sub-Saharan Africa. Brain 137, 2731-2742.

Cotelli, M., Manenti, R., Cappa, S.F., Geroldi, C., Zanetti, O., Rossini, P.M., Miniussi, C., 2006. Effect of transcranial magnetic stimulation on action naming in patients with Alzheimer disease. Arch. Neurol. 63, 1602-1604.

Davis, M.Y., Johnson, C.O., Leverenz, J.B., Weintraub, D., Trojanowski, J.Q., ChenPlotkin, A., Van Deerlin, V.M., Quinn, J.F., Chung, K.A., Peterson-Hiller, A.L., Rosenthal, L.S., Dawson, T.M., Albert, M.S., Goldman, J.G., Stebbins, G.T., Bernard, B., Wszolek, Z.K., Ross, O.A., Dickson, D.W., Eidelberg, D., Mattis, P.J., Niethammer, M., Yearout, D., Hu, S.C., Cholerton, B.A., Smith, M., Mata, I.F., Montine, T.J., Edwards, K.L., Zabetian, C.P., 2016. Association of GBA mutations and the E326K polymorphism with motor and cognitive progression in Parkison disease. JAMA Neurol. 73, 1217-1224.

Di Battista, M.E., Rubino, A., Valente, M., Giustini, P., Vanacore, N., Meco, G., 2016. Is cognitive stability in Parkinson's disease a predictable phenomenon? A 5-year follow up study. J. Neural. Transm. (Vienna) 122, 1703-1706.

Diederich, N.J., Moore, C.G., Leurgans, S.E., Chmura, T.A., Goetz, C.G., 2003. Parkinson disease with old-age onset. Arch. Neurol. 60, 529-533.

Ding, C., Ganesvaran, G., Alty, J.E., Clissold, B.G., McColl, C.D., Reardon, K.A., Schiff, M., Srikanth, V., Kempster, P.A., 2016. Study of levodopa response in Parkinson's disease: observations on rates of motor progression. Mov. Disord. 31, 589-592.

Dragasevic, N., Potrebic, A., Damjanovic, A., Stefanova, E., Kostic, V.S., 2002. Therapeutic efficacy of bilateral prefrontal slow repetitive transcranial magnetic stimulation in depressed patients with Parkinson's disease: an open study. Mov. Disord. 17, 528-532.

Elahi, B., Elahi, B., Chen, R., 2009. Effect of transcranial magnetic stimulation on Parkinson motor function: systematic review of cotrolled clinical trials. Mov. Disord. 24, 357-363.

Ellis, T.D., Cavanaugh, J.T., Earhart, G.M., Ford, M.P., Foreman, K.B., Thackeray, A., Thiese, M.S., Dibble, L.E., 2016. Identifying clinical measures that most accurately reflect the progression of disability in Parkinson disease. Parkinsonism Relat. Disord. 25, 65-71.

Erro, R., Picillio, M., Vitale, C., Amboni, M., Moccia, M., Santangeto, G., Pellecchia, M.T., Barone, P., 2016. The non-motor side of the honeymoon period of Parkinson's disease and its relationship with quality of life: a 4-year longitudinal study. Eur. J. Neurol. 23, 1673-1679.

Escott-Price, V., Nalls, M.A., Morris, H.R., Lubbe, S., Brice, A., Gasser, T., Heutink, P., Wood, N.W., Hardy, J., Singleton, A.B., Williams, N.M., 2015. Polygenic risk of Parkinson disease is correlated with disease age at onset. Ann. Neurol. 77, 582-591.

Evans, J.R., Mason, S.L., Williams-Gray, C.H., Foltynie, T., Trotter, M., Barker, R.A., 2011 The factor structure of the UPDRS as an index of disease progression in Parkinson's disease. J. Park. Dis. 1, 75-82.

Fahn, S., Elton, R., 1987. Members of the updrs Development Committee. In: In: Fahn, S., Marsden, C.D., Calne, D.B., Goldstein, M. (Eds.), Recent Developments in Parkinson'S Disease Vol. 2. Macmillan Health Care Information 153-163, Florham Park, NJ, pp. 293-304.

Fahn, S., Oakes, D., Shoulson, I., Kieburtz, K., Rudolph, A., Land, A., Olanow, C.W., Tanner, C., Marek, K., 2004. Levodopa and the progression of Parkinson's disease. N. Engl. J. Med. 351, 2498-2508.

Fierro, B., Giglia, G., Palermo, A., Pecoraro, C., Sealia, S., Brighina, F., 2007. Modulatory effect of $1 \mathrm{~Hz}$ rTMS over the cerebellum on motor cortex excitability. Exp. Brain Res. $176,440-447$.

Floel, A., Cohen, L.G., 2007. Contribution of noninvasive cortical stimulation to the study of memory functions. Brain Res. Rev. 53, 250-259.

Fraix, V., Bastin, J., David, O., Goetz, L., Ferraye, M., Benabid, A.L., Chabardes, S., Pollak, P., Debü, B., 2013. Pedunculopontine nucleus area oscillations during stance, stepping and freezing in Parkinson's disease. PLoS One 8, e83919.

Franca, C., de Andrade, D.C., Teixeira, M.J., Galhardoni, R., Silva, V., Barbosa, E.R., Cury, R.G., 2017. Effects of cerebellar neuromodulation in movement disorders: a systematic review. Brain Stim.(November (23)). http://dx.doi.org/10.1016/j.brs.2017. 11.015. pii;S1935-861X(17)30971-3.

Grimaldi, G., Argyropoulos, G.P., Bastian, A., Cortes, M., Davis, N.J., Edwards, D.J., Ferrucci, R., Fregni, F., Galea, J.M., Hamada, M., Manto, M., Miall, R.C., Morales Quezada, L., Pope, P.A., Priori, A., Rothwell, J., Tomlinson, S.P., Celnik, P., 2016. Cerebellar transcranial direct current stimulation (ctDCS): a novel approach to un derstanding cerebellar function in health and disease. Neuroscience 22, 83-97.

Guo, F., Han, X., Zhang, J., Zhao, X., Lou, J., Chen, H., Huang, X., 2014. Repetitive transcranial magnetic stimulation promotes neural stem cell proliferation via the regulation of MIR-25 in a rat model of focal cerebral ischemia. PLoS One 9.

Hanakawa, T., Katsumi, Y., Fukuyama, H., Honda, M., Hayashi, T., Kimura, J., Shibasaki, H., 1999. Mechanisms underlying gait disturbance in Parkinson's disease: a single photon emission computed tomography study. Brain 122, 1271-1282.

Hariri, A.R., Goldberg, T.E., Mattav, V.S., Kolachana, B.S., Callicott, J.H., Egan, M.F., Weinberger, D.R., 2003. Brain-derived neurotrophic factor val66met polymorphism 
affects human memory-related hippocampal activity and predicts memory performance. J. Neurosci. 23, 6690-6694.

Harrison, M.B., Wylie, S.A., Frysinge, R.C., Patrie, J.T., Huss, D.S., Currie, L.J., Wooten, G.F., 2009. UPDRS activity daily living score as marker of Parkinson's disease progression. Mov. Disord. 24, 224-230.

Hassanzahraee, M., Zoghi, M., Jaberzadeh, S., 2018. How different priming stimulations affect the corticospinal excitability induced by noninvasive brain stimulation techniques: a systematic review and meta analysis. Rev. Neurosci.(March (31)) Pii:/j/ revneuro.ahead-of-print/revneuro-2017-0111/revneuro-20170111.xml.doi:10.1515/revneuro-2017-0111. [Epub ahead of print].

Hauser, R.A., Holford, N.H.G., 2002. Quantitative description of loss of clinical benefit following withdrawal of levodopa-carbidopa and bromicriptin in early Parkinson's disease. Mov. Disord. 17, 961-968.

Hely, M.A., Morris, J.G.L., Reid, W.G.J., O'Sullivan, D.J., Williamson, P.M., Broe, G.A., Adena, M.A., 1995. Age at onset: the major determinant of outcome in Parkinson's disease. Ann. Neurol. Scand. 92, 455-463.

Hely, M.A., Morris, J.G.I., Traficante, R., Reid, W.G.J., O'Sullivan, D.J., Williamson, P.M., 1999. The Sydney multicentre study of Parkinson's disease: progression and mortality at 10 years. J. Neurol. Neurosurg. Psychiatry 67, 300-307.

Hely, M.A., Morris, J.G., Reid, W.G., Traficante, R., 2005. Sydney multicenter study of Parkinson's disease: non-L-dopa-responsive problems dominate at 15 years. Mov. Disord. 20, 190-199.

Hely, M.A., Reid, W.G., Adena, M.A., Halliday, G.M., Morris, J.G., 2008. The Sydney multicenter study of Parkinson's disease: the inevitability of dementia at 20 years. Mov. Disord. 23, 837-844.

Hershey, L.A., Feldman, B.J., Kim, K.Y., Commichau, C., Lichter, D.G., 1991. Tremor at onset. Predictor of cognitive and motor outcome in Parkinson's disease? Arch. Neurol. 48, 1049-1051.

Hoehn, M.M., Yahr, M.D., 1967. Parkinsonism: onset, progression, and mortality. Neurology 17, 427-442.

Huang, Y.Z., Lu, M.K., Antal, A., Classen, J., Nitsche, M., Ziemann, U., Ridding, M., Hamada, M., Igawa, Y., Jaberzadeh, S., Suppa, A., Paulus, W., Rothwell, J., 2017. Plasticity induced by non-invasive transcranial brain stimulation: a position paper. Clin. Neurophysiol. 128, 22318-22329.

Ilieva, I.P., Alexopoulos, G.S., Dubin, M.J., Morimoto, S.S., Victoria, L.W., Gunning, F.M., 2018. Age related repetitive transcranial magnetic stimulation effects on executive function in depression: a systematic review. Am. J. Geriatr. Psychiatry 26, 334-346.

Jahanshahi, M., Rothwell, J., 2000. Transcranial magnetic stimulation studies of cognition: an emerging field. Exp. Brain Res. 131, 1-9.

Jankovic, J., Kapadia, A.S., 2001. Functional decline in Parkinson disease. Arch. Neurol. $58,1611-1615$

Kavanaugh, B.C., Aaronson, S.T., Clarke, G.N., Holtzheimer, P.E., Johnson, C.W., McDonald, W.M., Schneider, M.B., Carpenter, L.L., 2018. Neurocognitive effects of repetitive transcranial magnetic stimulation with a 2-coil device in treatment-resistant major depressive disorder. J. ECT Doi: 10.1097/YCT.0000000000000494. [Epub ahead of print].

Kempster, P.A., Williams, D.R., Selikhova, M., Holton, J., Revesz, T., Lees, A.J., 2007. Patterns of levodopa response in Parkinson's disease: a clinico-pathological study. Brain 130, 2123-2128.

Khedr, E.M., Farweez, H.M., Islam, H., 2003. Therapeutic effect of repetitive transcranialmagnetic stimulation on motor function in Parkinson's disease patients. Eur. J. Neurol. 10, 567-572.

Khedr, E.M., Rothwell, J.C., Shawky, O.A., Ahmed, M.A., Hamdy, A., 2006. Effect of daily repetitive transcranial magnetic stimulation on motor performance in Parkinson's disease. Mov. Disord. 21, 1311-1316.

Klawans, H.L., 1986. Individual manifestations of Parkinson's disease after ten or more years of levodopa. Mov. Disord. 1, 187-192.

Knoll, J., Vizi, E.S., 1971. Effect of frequency of stimulation on the inhibition by noradrenaline of the acetylcholine output from parasympathetic nerve terminals. Br. J. Pharmacol. 42, 263-272.

Kojovic, M., Kassavetis, P., Bologna, M., Pareés, I., Rubio-Agusti, I., Beraredelli, A., Edwards, M.J., Rothwell, J.C., Bathia, K.P., 2015. Transcranial magnetic stimulation follow-up study in early Parkinson's disease: a decline in compensation with disease progression? Mov. Disord. 30, 1098-1106.

Lee, C.S., Schulzer, M., Mak, E.K., Snow, B.J., Tsui, J.K., Caine, S., Hammerstad, J., Caine, D.B., 1994. Clinical observations on the rate of progression of idiopathic parkinsonism. Brain 117, 501-507.

Lefaivre, S.C., Brown, M.J.N., Almeida, Q.J., 2016. Cerebellar involvement in Parkinson's disease resting tremor. Cerebellum Ataxias 3 (13). http://dx.doi.org/10.1186/ s40673-016-0051-5.

Lefaucheur, J.P., André-Obadia, N., Antal, A., Ayache, S.S., Baeken, C., Benninger, D.H., Cantello, R.M., Cincotta, M., de Carvalho, M., De Ridder, D., Devanne, H., Di Lazzaro, V., Filipovic, S.R., Hummel, F.C., Jääskeläinen, S.K., Kimiskidis, V.K., Koch, G., Langguth, B., Nyffeler, T., Oliviero, A., Padberg, F., Poulet, E., Rossi, S., Rossini, P.M., Rothwell, J.C., Schönfeldt-Lecuona, C., Siebner, H.R., Slotema, C.W., Stagg, C.J., Valls-Sole, J., Ziemann, U., Palus, W., Garcia-Larrea, L., 2014. Evidence-based guidelines on the therapeutic use of repetitive transcranial magnetic stimulation (rTMS). Clin. Neurophysiol. 125, 2150-2206.

Levy, G., 2007. The relationship of Parkinson disease with aging. Arch Neurol 64, $1242-1246$.

Li, Z.J., Wu, Q., Yi, C.J., 2015. Clinical efficacy of istradefylline versus rTMS on Parkinson's disease in a randomized clinical trial. Curr. Med. Res. Opin. 31, 2055-2058.

Lilleeng, B., Bronnick, K., Toft, M., Dietrichs, E., Larsen, J.P., 2014. Progression and survival in Parkinson's disease with subthalamic nucleus stimulation. Acta Neurol. Scand. 130, 292-298.
Lipsky, R.H., Marini, A.M., 2007. Brain derived neurotrophic factor in neuronal survival and behavior-related plasticity. Ann. N.Y. Acad. Sci. 1122, 130-143.

Liu, Y., Fan, J.H., Gao, X., Ma, L., Qiao, Y.L., Zhang, L., 2015a. The natural progression of Parkinson's disease in a small cohort with 15 drug-naive patients. Chin. Med. J (Engl.) 128, 1761-1764.

Liu, H., Han, X.H., Chen, H., Zheng, C.X., Yang, Y., Huang, X.L., 2015b. Repetitive magnetic stimulation promotes neural stem cells proliferation by upregulating MIR106b in vitro. J. Huazhong Univ. Sci. Technol. Med. Sci. 35, 766-772.

Lomarev, M.P., Kanchana, S., Bara-Jimenez, W., Iyer, M., Wassermann, E.M., Hallett, M., 2006. Placebo-controlled study of rTMS for the treatment of Parkinson's disease. Mov. Disord. 21, 325-331.

Lorincz, T., Kisfali, M., Lendvai, B., Vizi, E.S., 2016. Phenotype-dependent Ca(2+) dynamics in single boutons of various anatomically identified GABAergic interneurons in the rat hippocampus. Eur. J. Neurosci. 43, 536-547.

Louis, A.D., Tang, M.X., Cote, L., Alfaro, B., Mejlia, H., Marder, K., 1999. Progression of Parkinsonian signs in Parkinson disease. Arch. Neurol. 56, 334-337.

Luo, J., Zheng, H., Zhang, L., Zhang, Q., Li, L., Pei, Z., Hu, X., 2017. High-frequency repetitive transcranial magnetic stimulation (rTMS) improves functional recovery by enhancing neurogenesis and activating BDNF/TrkB signaling in ischemic rats. Int. J. Mol. Sci. 18http://dx.doi.org/10.3390/ljms18020455. pii: E455.

Maetzler, W., Liepelt, I., Berg, D., 2009. Progression of Parkinson's disease in the clinical phase: potential markers. Lancet Neurol. 8, 1158-1171.

Mally, J., 2013. Non-invasive brain stimulation (rTMS and tDCS) in patients with aphasia: mode of action at the cellular level. Brain Res. Bull. 98, 30-35.

Málly, J., Stone, T.W., 1998. Lasting improvement in parkinsonian symptoms after repetitive transcranial magnetic stimulation. Med. Sci. Res. 26, 521-523.

Málly, J., Stone, T.W., 1999a. Improvement in Parkinsonian symptoms after repetitive magnetic stimulation. J. Neurol. Sci. 162, 179-184.

Málly, J., Stone, T.W., 1999b. Therapeutic and "dose dependent" effect of repetitive mikroelectroshock induced by transcranial magnetic stimulation in Parkinson's disease. J. Neurosci. Res. 57, 935-940.

Málly, J., Farkas, R., Tóthfalusi, L., Stone, T.W., 2004. Long term follow-up study with repetitive trascranial magnetic stimulation (rTMS) in Parkinson's disease. Brain Res. Bull. 64, 259-263.

Málly, J., Geisz, N., Dinya, E., 2017. Follow-up study: the influence of rTMS with high and low frequency stimulation on motor and executive function in Parkinson's disease. Brain Res. Bull. 135, 98-104.

Manto, M., Ben Taib, N.O., 2008. A novel approach for treating cerebellar ataxias. Med. Hypotheses 71, 58-60.

Marras, C., Rochon, P., Lang, A.E., 2002. Predicting motor decline and disability in Parkinson's disease: a systematic review. Arch. Neurol. 59, 1724-1728.

Matko, I., Feher, E., Vizi, E.S., 1994. Receptor mediated presynaptic modulation of the release of noradrenaline in human papillary muscle. Cardiovasc. Res. 28, 700-704.

Medina-Fernandez, F.J., Escribano, B.M., Luque, E., Caballero-Villarraso, J., GomezChaparro, J.L., Feijoo, M., Garcia-Maceira, F.I., Pascual-Leone, A., Drucker-Colin, R., Tunez, I., 2018. Comparative of transcranial magnetic stimulation and other treatments in experimental autoimmune encephalitis. Brain Res. Bull. 137, 140-145.

Mendes, A., Goncalves, A., Vila-Chä, N., Calejo, M., Moreira, I., Fernandes, J., Damásio, J., Teixeira-Pinto, A., Krack, P., Lima, A.B., Cavaco, S., 2016. Statistical models of Parkinson's disease progression: predictive validity in a 3-year follow-up. J. Parkinsons Dis. 6, 793-804.

Mentis, M.J., Dhawan, V., Nakamura, T., Ghilardi, M.F., Feigin, A., Edwards, C., Ghez, C., Eidelberg, D., 2003. Enhancement of brain activation during trial-and-error sequence learning in early PD. Neurology 60, 612-619.

Milusheva, E.A., Doda, M., Baranyi, M., Vizi, E.S., 1996. Effect of hypoxia and glucose deprivation on ATP level, adenylate energy charge and $[\mathrm{Ca} 2+]$ o-dependent and independent release of $[3 \mathrm{H}]$ dopamine in rat striatal slices. Neurochem. Int. 28, 501-507.

Moccia, M., Erro, R., Picillo, M., Vitale, C., Longo, K., Amboni, M., Pellecchia, M.T., Barone, P., 2016. Caffeine consumption and the 4-year progression of de novo Parkinson's disease. Parkinsonian Relat. Disord. 32, 116-119.

Müller, M.B., Toschi, N., Kresse, A.E., Post, A., Keck, M.E., 2000. Long-term repetitive transcranial magnetic stimulation increases the expression of brain-derived neurotrophic factor and cholecystokinin mRNA, but not neuropeptide tyrosine mRNA in specific areas of rat brain. Neuropsychopharmacology 23, 205-2015.

Olanow, C.W., Rascol, O., Hauser, R., Feigin, P.D., Jankovic, J., Lang, A., Langston, W., Melamed, E., Poewe, W., Stocchi, F., Tolosa, E., ADAGIO Study Investigators, 2009. A double blind, delayed-start trial of rasargiline in Parkinson's disease. N. Engl. J. Med. $361,1268-1278$.

Pál, E., Nagy, F., Aschermann, Z., Balázs, E., Kovács, N., 2010. The impact of left prefrontal repetitive trasncranial magnetic stimulation on depression in Parkinson's disease: a randomized, double-blind, placebo controlled study. Mov. Disord. 25, 2311-2317.

Park, E., Kang, M.J., Lee, A., Chang, W.H., Shin, Y.I., Kim, Y.-H., 2017. Real time measurement of cerebral blood flow during and after repetitive transcranial magnetic stimulation: a near-infrared spectroscopy study. Neurosci. Lett. 653, 78-83.

Parkinson Study Group, 2004. Levodopa and the progression of Parkinson's disease. N. Eng. J. Med. 351, 2498-2508.

Paul, K.C., Rausch, R., Creek, M.M., Sinscheimer, J.S., Bornstein, J.M., Bordelon, Y., Ritz, B., 2016. APOE, MAPT, and COMT and Parkinson's disease susceptibility and cognitive symptom progression. J. Parkinsons Dis. 6, 349-359.

Pedersen, K.F., Larsen, J.P., Tysnes, O.B., Alves, G., 2017. Natural course of mild cognitive impairment in Parkinson disease: a 5-year population based study. Neurology 88, 7676-7774.

Poewe, W., 2009. Clinical measures of progression in Parkinson's disease. Mov. Disord. 24, S671-S676. 
Post, B., Merkus, M.P., de Haan, R.J., Speelman, J.D., on behalf of the CARPA Study Group, 2007. Prognostic factors for the progression of Parkinson's disease: a systematic review. Mov. Disord. 22, 1839-1851.

Post, B., Muslimovic, D., van Geloven, N., Speelman, J.D., Schmand, B., de Haan, R.J., CARPA-study group, 2011. Progression and prognostic factors of motor impairment, disability and quality of life in newly diagnosed Parkinson's disease. Mov. Disord. 26, 449-456.

Rascol, O., Hauser, R.A., Stocchi, E., Fitzer-Attas, C.J., Sidi, Y., Abler, V., Olanow, C.W., Investigators, A.F.U., 2016. Long-term effects of rasagiline and the natural history of treated Parkinson's disease. Mov. Disord. 31, 1489-1496.

Reinoso, G., Allen, J.C., Au, W.L., Seah, S.H., Tay, K.Y., Tan, L.C., 2014. Clinical evolution of Parkinson's disease and prognostic factors affecting motor progression: 9-year follow-up study. Eur. J. Neurol. 30, 1098-1106.

Reitan, R.M., 1992. Trail Making Test: Manual for Administration and Scoring. Reitan Neuropsychology Laboratory, Tuscon, AZ.

Rektorova, I., Megova, S., Bares, M., Rektor, I., 2005. Cognitive functioning after repetitive transcranial magnetic stimulation in patients with cerebrovascular disease without dementia: a pilot study of seven patients. J. Neurol. Sci. 15, 229-230.

Schniepp, R., Möhwald, K., Wuehr, M., 2017. Gait ataxia in humans: vestibular and cerebellar control of dynamic stability. J. Neurol. 264 (Suppl. 1), 87-92.

Schrag, A., Dodel, R., Spottke, A., Bornschein, B., Siebert, U., Quinn, N.P., 2007. Rate of clinical progression in Parkinson's disease. A prospective study. Mov. Disord. 22, 938-945.

Schweder, P.M., Hansen, P.C., Green, A.L., Quaghebeur, G., Stein, J., Aziz, T.Z., 2010. Connectivity of the peduncolopontine nucleus in Parkinsonian freezing of gait. Neuroreport 21, 914-916.

Shirota, S., Ontsu, H., Hamada, M., Enomoto, H., Ugawa, Y., 2013. Research committee on rTMS treatment of Parkinson's disease, supplementary motor area stimulation for Parkinson disease: a randomized controlled study. Neurology 80, 1400-1405.

Simon, D.K., Wu, C., Tilley, B.C., Wills, A.M., Aminoff, M.J., Bainbridge, J., Hauser, R.A., Schneider, J.S., Sharma, S., Singer, C., Tanner, C.M., Truong, D., Wong, P.S., 2015. Caffein and progression of Parkinson disease: a deleterious interaction with creatine. Clin. Neuropharmacol. 38, 163-169.

Simon, D.K., Wu, C., Tilley, B.C., Lohmann, K., Klein, C., Payami, H., Wills, A.M., Aminoff, M.J., Bainbridge, J., Dewey, R., Hauser, R.A., Schaake, S., Schneider, J.S., Sharma, S., Singer, C., Tanner, C.M., Truong, D., Wei, P., Wong, P.S., Yang, T., 2017. Caffeine, creatin, GRIN2A and Parkinson's disease progression. J. Neurol. Sci. 375, 355-359.

Sircuta, C., Lazar, A., Azamfirei, L., Baranyi, M., Vizi, E.S., Borbely, Z., 2016. Correlation between the increased release of catecholamines evoked by local anesthetics and their analgesic and adverse effects: role of $\mathrm{K}(+)$ channel inhibition. Brain Res. Bull. 124, 21-26.

Spica, V., Pekmezovic, T., Svetel, M., Kostic, V.S., 2013. Prevalence of non-motor symptoms in young-onset versus late-onset Parkinson's disease. J. Neurol. 260 131-137.

Strafella, A.P., Paus, T., Barrett, J., Dagher, A., 2001. Repetitive transcranial magnetic stimulation of the human prefrontal cortex induces dopamine release in the caudate nucleus. J. Neurosci. 21, RC157.

Strafella, A.P., Ko, J.H., Grant, J., Fraraccio, M., Monchi, O., 2005, Corticostriatal functional interactions in Parkinson's disease: a rTMS [11C] raclopide PET study. Eur. J. Neurosci. 22, 2946-2952.

Ueyama, E., Ukai, S., Ogawa, A., Yamamoto, M., Kawaguchi, S., Isgii, R., Shinosaki, K., 2011. Chronic repetitive trasncranial magnetic stimulation increases hippocampal neurogenesis in rats. Psychiatry Clin. Neurosci. 65, 77-81.

Umeda, E., Satoh, T., Nagashima, H., Potter, P.E., Tarkovacs, G., Vizi, E.S., 1997. Alpha 2A subtype of presynaptic alpha 2-adrenoceptors modulates the release of [3H]noradrenaline from rat spinal cord. Brain Res. Bull. 42, 129-132.

Vegh, D., Somogyi, A., Banyai, D., Lakatos, M., Balogh, M., Al-Khrasani, M., Furst, S., Vizi, E.S., Hermann, P., 2017. Effects of articaine on [(3)H]noradrenaline release from cortical and spinal cord slices prepared from normal and streptozotocin-induced diabetic rats and compared to lidocaine. Brain Res. Bull. 135, 157-162.

Vizi, E.S., 1984. Non-Synaptic Interactions between Neurons: Modulation of Neurochemical 1Transmission. Pharmacological and Clinical Aspects. John Wiley and Sons, Chichester, New York.

Vizi, E.S., 2000. Role of high-affinity receptors and membrane transporters in nonsynapticcommunication and drug action in the central nervous system. Pharmacol. Rev. 52, 63-89.

Vizi, E.S., Burnstock, G., 1988. Origin of ATP release in the rat vas deferens: concomitantmeasurement of 3H noradrenaline and 14C ATP. Eur. J. Pharm. 158, 69-77.

Vizi, E.S., Hársing, L.G., Zsilla, G., 1981. Evidence of the modulatory role of serotonin in acetylcholine release from striatal interneurones. Brain Res. 212, 89-99.

Vizi, E.S., Kobayashi, O., Torocsik, A., Kinjo, M., Nagashima, H., Manabe, N., Goldiner, P.L., Potter, P.E., Foldes, F.F., 1989. Heterogeneity of presynaptic muscarinic receptors involved in modulation of transmitter release. Neuroscience 31, 259-267.

Vizi, E.S., Tóth, I.E., Orsó, E., Szalay, K.Sz., Szabó, D., Baranyi, M., Vinson, G.P., 1993. Dopamine is taken up from the circulation by, and released from, local noradrenergic varicose axon terminals in zona glomerulosa of the rat: a neurochemical and immunocytochemical study. J. Endecrinol. 139, 213-226.

Vizi, E.S., Fekete, A., Károly, R., Mike, A., 2010. Non-synaptic receptors and transportersinvolved in brain functions and targets of drug treatment. Br. J. Pharmacol. 160, 785-809.

Wangle, S.A., Shuster, J.J., Chung, J.W., Vaillancourt, D.E., Patten, C., Ostrem, J.L., 2016 rTMS therapy in Parkinson's disease: a meta-analysis. PMRJ 8, 356-366.

Wickremaratchi, M.M., Ben-Shiomo, Y., Morris, H.R., 2009. The effect of onset age on the clinical features of Parkinson's disease. Eur. J. Neurol. 16, 450-456.

Williams-Gray, C.H., Mason, S.L., Evans, J.R., Foltynie, T., Brayne, C., Robbins, T.W., Barker, R.A., 2013. The CamPalGN study of parkinson's disease: 10-year outlook in an incident population-based cohort. J. Neurol. Neurosurg. Psychiatry 84 , 1258-1264.

Wu, T., Hallett, M., 2013. The cerebellum in Parkinson's disease. Brain 136, 696-709.

Zhu, H., Lu, Z., Jin, Y., Youn, X., Teng, J., Duan, D., 2015. Low-frequency repetitive tramscranial magnetic stimulation on Parkinson motor function: a meta-analysis of randomised controlled trials. Acta Neuropsychiatry 27, 82-89. 